\title{
CONSTRUÇÃO E OTIMIZAÇÃO DE UM REATOR DE BAIXO CUSTO PARA A FOTODEGRADAÇÃO DA MATÉRIA ORGÂNICA EM ÁGUAS NATURAIS E SUA APLICAÇÃO NO ESTUDO DA ESPECIAÇÃO DO COBRE POR VOLTAMETRIA
}

\author{
M. Lúcia A. M. Campos*, Lígia C. Mello, Dilson R. Zanette, M. Marta de Souza Sierra e Anderson Bendo
}

Departamento de Química, Universidade Federal de Santa Catarina, 88040-900 Florianópolis - SC

Recebido em 17/4/00; aceito em 2/8/00

\begin{abstract}
CONSTRUCTION AND OPTIMIZATION OF A LOW COST REACTOR FOR THE PHOTODEGRADATION OF ORGANIC MATTER FROM NATURAL WATERS AND ITS APPLICATION FOR THE STUDY OF COPPER SPECIATION BY VOLTAMMETRY. This work describes the construction of a home-made low-cost reactor, using easily available materials, capable of destroying efficiently dissolved organic matter. Just 30 minutes of irradiation were sufficient to destroy more than $99 \%$ of the humic acids present in a solution of $4 \mathrm{mg} \mathrm{C} \mathrm{L}^{-1}$. Copper speciation was evaluated in natural waters of different salinities to test the reactor's efficiency in destroying organically complexed metal species. The effect of the organic matter concentration, salinity, dissolved oxygen and temperature in the photo-oxidation process is discussed.
\end{abstract}

Keywords: photodegradation; organic matter; trace metal speciation.

\section{INTRODUÇÃO}

As voltametrias de redissolução catódica e anódica vêm sendo amplamente utilizadas no estudo da especiação química de metais-traço em águas de diversos tipos de ecossistemas naturais, por serem técnicas de grande sensibilidade e seletividade ${ }^{1}$. Entretanto, a matéria orgânica presente nas águas naturais interfere na determinação da concentração de metais por voltametria principalmente de duas maneiras: 1) pela formação de fortes complexos com metais, os quais não são detectados durante a análise da amostra, levando à quantificação apenas da fração eletroquimicamente lábil; e 2) competindo com o metal pela superfície do eletrodo, diminuindo assim a intensidade do sinal do analito ou provocando o aparecimento de sinais interferentes $^{2}$. Assim, a destruição dos complexos orgânicos torna-se uma etapa fundamental na análise de metais por voltametria. Outros métodos que sofrem interferência da matéria orgânica dissolvida no meio, como por exemplo, aqueles que utilizam resinas trocadoras de íons para a pré-concentração de metais dependem igualmente de etapas que suprimam a matéria orgânica interferente ${ }^{3}$. Os métodos de digestão úmida, que empregam aquecimento e adição de reagentes como ácidos oxidantes ou peróxido, têm sido bastante utilizados, mas apresentam a desvantagem de oferecer um alto risco de contaminação, principalmente no caso de amostras com metais no nível de traço.

A concentração da matéria orgânica dissolvida em águas naturais, avaliada na forma de carbono orgânico dissolvido (COD), pode variar de aproximadamente $0,1 \mathrm{mg} \mathrm{C} \mathrm{L}^{-1} \mathrm{em}$ águas oceânicas, até cerca de $50 \mathrm{mg} \mathrm{C} \mathrm{L}^{-1}$ em rios ou lagos de alta produtividade ${ }^{4}$. De 40 a $80 \%$ desse material é formado por substâncias húmicas, que são macromoléculas de estrutura complexa e composição elementar variável ${ }^{4}$. Grupos cromóforos como ácidos carboxílicos e estruturas aromáticas são abundantes nos compostos húmicos, que absorvem fortemente a luz ultravioleta e podem atuar como fotossensibilizadores ${ }^{5}$. Os fotossensibilizadores são moléculas que quando excitadas transferem sua energia de excitação para outras moléculas presentes em solução, podendo formar espécies altamente reativas como radical hidroxila $(\cdot \mathrm{OH})$, peróxido de hidrogênio $\left(\mathrm{H}_{2} \mathrm{O}_{2}\right)$, oxigênio

*e-mail: 1campos@qmc.ufsc.br singlete $\left({ }^{1} \mathrm{O}_{2}\right)$, íon superóxido $\left(\mathrm{O}_{2}^{-\cdot}\right)$ e elétron hidratado $\left(\mathrm{e}_{\text {hid }}^{-}\right)^{5}$. Essas novas espécies podem foto-oxidar os próprios fotossensibilizadores, como também outros compostos orgânicos se presentes em solução. Portanto, na presença de uma fonte contínua e intensa de radiação ultravioleta a fotodegradação da matéria orgânica pode ser bastante rápida e eficiente ${ }^{6}$.

Diversos métodos vêm sendo utilizados para avaliar a concentração de COD em amostras naturais. Um dos métodos mais utilizados é aquele que emprega alta temperatura e catalisador de platina para a total oxidação do carbono orgânico para $\mathrm{CO}_{2}$ e detecção por absorção em infravermelho ${ }^{7}$. Este método também vem sendo utilizado para acompanhar a fotodegradação de uma variedade de compostos orgânicos ${ }^{8}$. A análise de $\mathrm{CO}_{2}$ utilizando injeção em fluxo com detecção condutimétrica, foi empregada por Jardim e colaboradores ${ }^{9}$ como uma alternativa mais barata, porém menos sensível, para acompanhar a mineralização da matéria orgânica. A espectrometria de fluorescência tem sido uma ferramenta bastante útil na quantificação e principalmente, na caracterização de compostos húmicos de distintas origens, devido à presença de um grande número de grupos fluoróforos nesses compostos ${ }^{10}$.

Este trabalho aborda a construção de um reator artesanal bastante simples e de baixo custo, que utiliza uma fonte de radiação ultravioleta para destruição da matéria orgânica de maneira eficiente e com baixo risco de contaminação. A destruição da matéria orgânica durante a irradiação de soluções de ácido húmico comercial, foi monitorada pela atenuação do sinal de fluorescência. Com o objetivo de testar a eficiência do reator na destruição da matéria orgânica natural, e demonstrar sua aplicabilidade no estudo da especiação química de metais, as concentrações de cobre em amostras naturais de distintos ambientes foram avaliadas por voltametria de redissolução catódica, antes e depois de serem submetidas à irradiação.

\section{PARTE EXPERIMENTAL}

Uma solução estoque de $60 \mathrm{mg} \mathrm{C} \mathrm{L}^{-1}$ de ácido húmico comercial Aldrich $(38,4 \% \mathrm{C}, 4,3 \% \mathrm{H}$ e $0,28 \% \mathrm{~N})$ foi preparada em água destilada e desionizada (Milli-Q) e preservada em geladeira por no máximo 3 meses. Soluções em triplicata de ácido húmico $(\mathrm{AH})$ de $4,6,8,12$ e $30 \mathrm{mg} \mathrm{C} \mathrm{L}^{-1}$ foram submetidas à irradiação UV em tubos de quartzo, retirando-se uma 
alíquota de aproximadamente $3 \mathrm{ml}$ de cada tubo em diversos intervalos de tempo para análise fluorimétrica. A intensidade de fluorescência de emissão das soluções foi avaliada usando um fluorímetro de marca Perkin Elmer, modelo EFLS5B e cubeta de quartzo com caminho óptico de $1 \mathrm{~cm}$. O comprimento de onda de excitação foi de $313 \mathrm{~nm}$, a varredura realizada de 330 a $600 \mathrm{~nm}$ e as larguras da fenda de excitação e de emissão foram de 10 e $2,5 \mathrm{~nm}$ respectivamente.

Amostras de superfície de águas naturais foram coletadas diretamente em frascos de polietileno pré-lavados, imediatamente filtradas em sistema fechado de polissulfona sob pressão de nitrogênio utilizando membranas de acetato de celulose de poro $0,45 \mu \mathrm{m}$. As alíquotas reservadas para análise de metal dissolvido total foram acidificadas para $\mathrm{pH} 2$ antes de serem preservadas em congelador. As concentrações de cobre nas amostras naturais foram avaliadas por voltametria de redissolução catódica utilizando o ligante salicilaldoxima ${ }^{11}$ da marca Sigma. O sistema voltamétrico consistiu de um potenciostato PAR 263A, sistema de eletrodo PAR 303A com eletrodo de gota pendente de mercúrio, eletrodo de referência $\mathrm{Ag} /$ $\mathrm{AgCl}$ e eletrodo auxiliar de platina, controlados por um computador pessoal 4DX2, processador 486. O padrão de cobre de $1 \times 10^{-6} \mathrm{~mol} \mathrm{~L}^{-1}$ foi obtido após diluições sucessivas do padrão de 1000 ppm SpectrosoL, Merck. Os reagentes $\mathrm{H}_{2} \mathrm{O}_{2}, \mathrm{NaCl}$, $\mathrm{MgSO}_{4} .7 \mathrm{H}_{2} \mathrm{O}$ e $\mathrm{NaHCO}_{3}$ utilizados foram de grau analítico. $\mathrm{O}$ $\mathrm{pH}$ das soluções foram avaliados utilizando pHmetro e eletrodo de vidro combinado da marca ORION.

\section{Construção do reator}

Para a construção do corpo do reator, foi utilizado um cilindro de aço inoxidável de $12 \mathrm{~cm}$ de diâmetro e $20 \mathrm{~cm}$ de altura, com tampas também do mesmo material (Figura 1). Como a temperatura da lâmpada tende a se elevar, o sistema deve ser resfriado para evitar a evaporação das amostras. Foram feitos 12 orifícios de aproximadamente $1 \mathrm{~cm}$ de diâmetro na base do reator, e na tampa adaptou-se o ventilador da CPU de um antigo computador (DC $12 \mathrm{~V} ; 0,12 \mathrm{~A}$ ) para sugar o ar interno e refrigerar o sistema. Ao ventilador foi acoplado um conversor que permitiu ajustar a velocidade e, conseqüentemente, a temperatura para $70{ }^{\circ} \mathrm{C}$ durante o processo de digestão. Foram fixados suportes metálicos no corpo do reator para o uso de até 5 tubos de quartzo com $2,5 \mathrm{~cm}$ de diâmetro externo, 1,9 cm de diâmetro interno, e $15 \mathrm{~cm}$ de altura. Devido à grande exposição lateral dos tubos à irradiação, suas tampas foram confeccionadas com vidro comum.

Lâmpadas de mercúrio de alta e baixa pressão, entre 14 e até $1000 \mathrm{~W}$ de potência vêm sendo empregadas como fonte de radiação ultravioleta para destruição da matéria orgânica ${ }^{6,12,13}$. Neste trabalho, a fonte de radiação ultravioleta utilizada foi aquela fornecida por uma lâmpada de vapor de mercúrio de alta pressão de $125 \mathrm{~W}$ fabricada pela Philips (HPL-N), cujo bulbo externo foi removido para total exposição das amostras à radiação. Este tipo de lâmpada é muito utilizado no Brasil para iluminação de ruas.

\section{RESULTADOS E DISCUSSÃO}

\section{Otimização do reator}

Visto que a matéria orgânica natural é formada principalmente por substâncias húmicas, a otimização das condições de fotólise foi realizada utilizando soluções de ácido húmico comercial, que serviu como modelo de compostos orgânicos de alto peso molecular.

Os espectros de emissão das soluções de $\mathrm{AH} 4,8$ e $15 \mathrm{mg}$ $\mathrm{C} \mathrm{L}^{-1}$ foram acompanhados usando os comprimentos de onda de excitação $\left(\lambda_{\text {exc }}\right)$ de $313 \mathrm{~nm}$ e $370 \mathrm{~nm}$, pois nesses comprimentos de onda se esperava obter espectros de fluorescência para a matéria orgânica dissolvida com boa definição e alta sensibilidade $^{14}$. Porém, os espectros de emissão $\operatorname{com} \lambda_{\mathrm{exc}}=313$ $\mathrm{nm}$ apresentaram um máximo melhor definido, sendo este comprimento de onda utilizado em todos os experimentos seguintes. $\mathrm{O}$ pH das soluções de $\mathrm{AH}$ não foi ajustado para um valor fixo, visto que em águas naturais este também é variável.

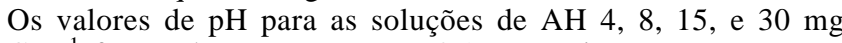
$\mathrm{C} \mathrm{L} \mathrm{L}^{-1}$ foram de 6,$6 ; 6,9 ; 7,6$ e 8,1 respectivamente.

A fotodegradação de uma solução de $\mathrm{AH} 8 \mathrm{mg} \mathrm{C} \mathrm{L}^{-1}$ foi acompanhada através dos espectros de emissão de fluorescência, antes, e depois da irradiação por diversos intervalos de tempo (Figura 2). O sinal de fluorescência decresceu gradativamente, até que após 2 horas de irradiação, o espectro desta solução não mais diferiu do espectro da água desionizada. Estima-se que a concentração de carbono residual após a destruição da matéria orgânica seja $<0,01 \mathrm{mg} \mathrm{C} \mathrm{L}^{-1}$, pois o espectro de fluorescência obtido para uma solução de $\mathrm{AH} 0,01 \mathrm{mg} \mathrm{C} \mathrm{L}^{-1}$ foi visualmente

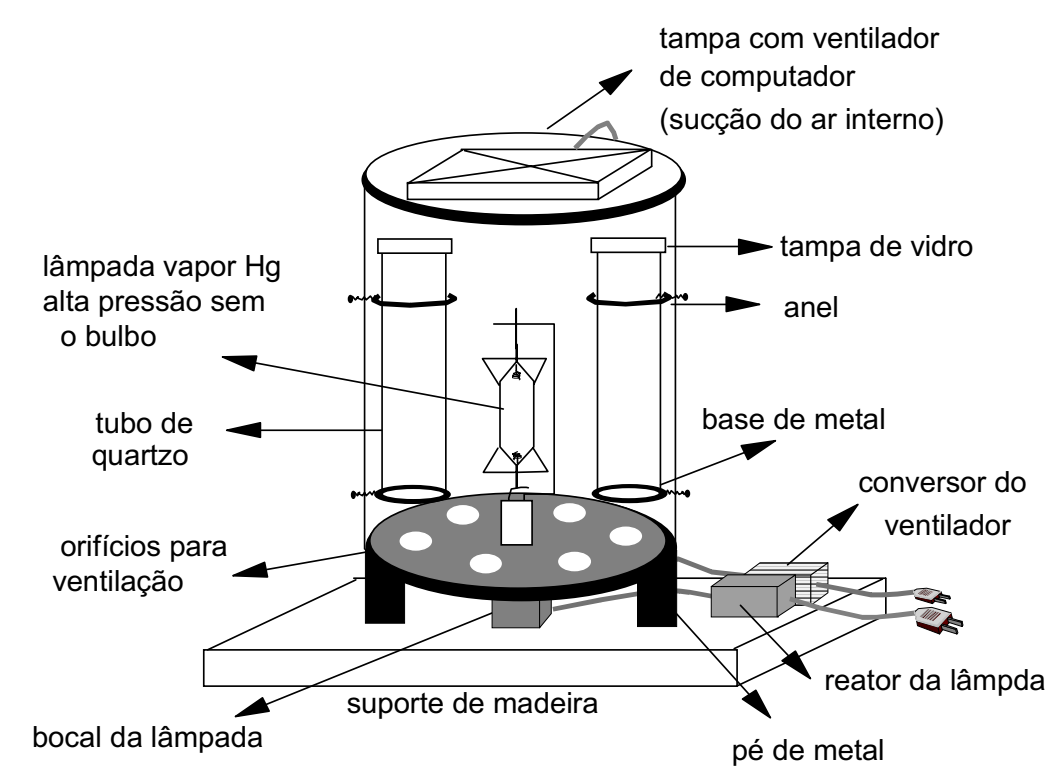

Figura 1. Desenho do reator construído artesanalmente com as escalas aproximadas. São mostrados apenas 2 tubos de quartzo, mas há espaço para 5 no total. 
distinto do espectro da água irradiada por 4 horas, tanto em termos de intensidade, como em termos de máximo de emissão. Para soluções de AH de concentrações menores que 0,01 mg $\mathrm{C} \mathrm{L} \mathrm{L}^{-1}$ essa distinção não foi clara.

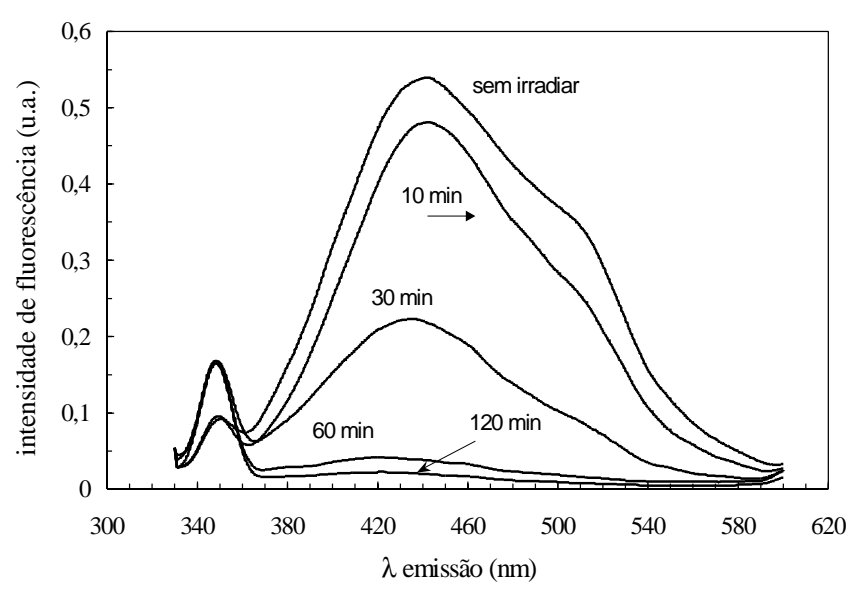

Figura 2. Espectros de emissão de fluorescência em unidades arbi-

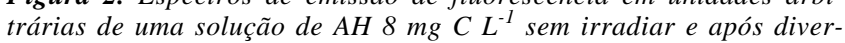
sos períodos de irradiação.

Uma alíquota da solução de AH $8 \mathrm{mg} \mathrm{C} \mathrm{L}^{-1}$ foi colocada sobre a bancada do laboratório em contato com a luz ambiente por 8 horas, e outra foi mantida no escuro. Em ambos os casos não houve alteração aparente nos espectros das soluções, e portanto, as variações espectrais observadas durante o processo de degradação são atribuídas à radiação da lâmpada de vapor de mercúrio. Não foi observada perda de massa nas soluções irradiadas por até 4 horas a uma temperatura de $\sim 70{ }^{\circ} \mathrm{C}$, excluindo assim a possibilidade de um aumento na concentração do analito durante a irradiação por evaporação do solvente. A taxa de oxidação de uma solução de $\mathrm{AH} 8 \mathrm{mg} \mathrm{C} \mathrm{L}^{-1}$ foi reduzida em até 4 vezes quando a temperatura de irradiação foi reduzida de $\sim 70{ }^{\circ} \mathrm{C}$ para $\sim 40{ }^{\circ} \mathrm{C}$, demonstrando que temperaturas relativamente altas auxiliam na destruição dos compostos húmicos. Desta forma, a temperatura de $\sim 70{ }^{\circ} \mathrm{C}$ foi fixada para os demais experimentos ajustando a velocidade do ventilador.

Visto que a fluorescência máxima de várias soluções de AH se deu por volta de $441 \mathrm{~nm}$, este comprimento de onda foi escolhido para expressar a eficiência do reator na destruição da matéria orgânica. Após meia hora de irradiação a solução de AH $4 \mathrm{mg} \mathrm{C} \mathrm{L}^{-1}$ apresentou uma redução na fluorescência de $99 \pm 0,3 \%$ (Figura 3). No caso da solução de AH $6 \mathrm{mg} \mathrm{C}$ $\mathrm{L}^{-1}$, para atingir uma eficiência $>98 \%$ foi necessário 1 hora de irradiação, e para as soluções de AH 8 e $12 \mathrm{mg} \mathrm{C} \mathrm{L}^{-1}, 2$ horas. Achterberg e van den Berg ${ }^{6}$, usando uma lâmpada de vapor de mercúrio de $100 \mathrm{~W}$ e tubos de quartzo, relataram que foram necessárias 4 horas para haver completa destruição de uma solução de $\mathrm{AH} 7,75 \mathrm{mg} \mathrm{C} \mathrm{L}^{1-}$, e 5,5 horas para atingir uma degradação > 99\% para uma solução de AH $15 \mathrm{mg} \mathrm{C} \mathrm{L}^{-1}$. Porém, quando esses autores utilizaram a mesma lâmpada, mas em um sistema onde a solução dentro de uma espiral de quartzo era irradiada em fluxo $(\phi$ interno $=1,0 \mathrm{~mm}$; comprimento $=4,4 \mathrm{~m}$ e volume $=3,47 \mathrm{ml}$ ) o tempo necessário para atingir uma eficiência $>99,5 \%$ foi de apenas 4,6 minutos para ambas as soluções. Isto vem demonstrar a importância da superfície de exposição durante o processo de irradiação.

$\mathrm{O}$ grande desvio padrão observado na Figura 3 para as soluções de $\mathrm{AH} 8$ e $12 \mathrm{mg} \mathrm{C} \mathrm{L}^{-1}$ demonstra que houve uma grande variação na eficiência da fotodegradação dessas soluções. Esta variação está provavelmente relacionada com a quebra não uniforme da estrutura molecular dos compostos húmicos, uma vez que não foi observada uma diferença sistemática na eficiência da degradação de acordo com a posição das amostras dentro do reator. No caso da solução de $\mathrm{AH} 12 \mathrm{mg} \mathrm{C} \mathrm{L}^{-1}$, observou-se um aumento do sinal relativo após 30 minutos de irradiação devido à diminuição inicial da eficiência de fluorescência, provocada pela alta concentração de grupos fluoróforos em solução. De fato, uma grande concentração de grupos fluorescentes promove a reabsorção da fluorescência emitida, atenuando assim a intensidade de emissão esperada. A Figura 4 mostra que para soluções de $\mathrm{AH} \geq 2 \mathrm{mg} \mathrm{C} \mathrm{L}^{-1}$, a atenuação da intensidade de fluorescência já se torna aparente. A destruição parcial de algumas estruturas moleculares durante o processo de oxidação pode minimizar este efeito, aumentando assim a intensidade do sinal após a irradiação da solução.

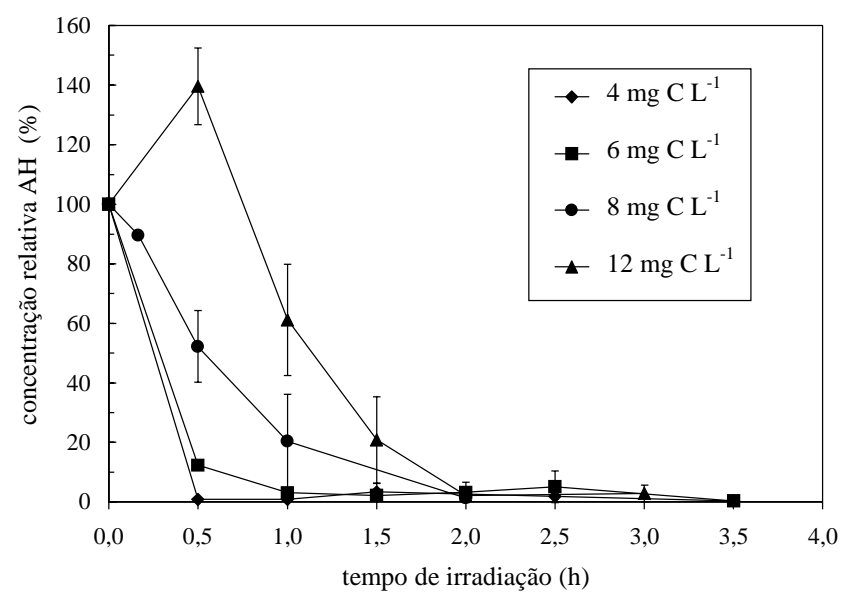

Figura 3. Concentração relativa de ácido húmico expressa como porcentagem do sinal inicial de fluorescência de emissão em $441 \mathrm{~nm}$, de acordo com o tempo de irradiação. A irradiação das soluções foi realizada em triplicata ( 3 tubos de quartzo), e a cada intervalo de tempo uma alíquota de cada tubo era retirada para análise, sendo mostrados no gráfico a média e desvio padrão relativo da fluorescência $(n=3)$ para soluções de diversas concentrações.

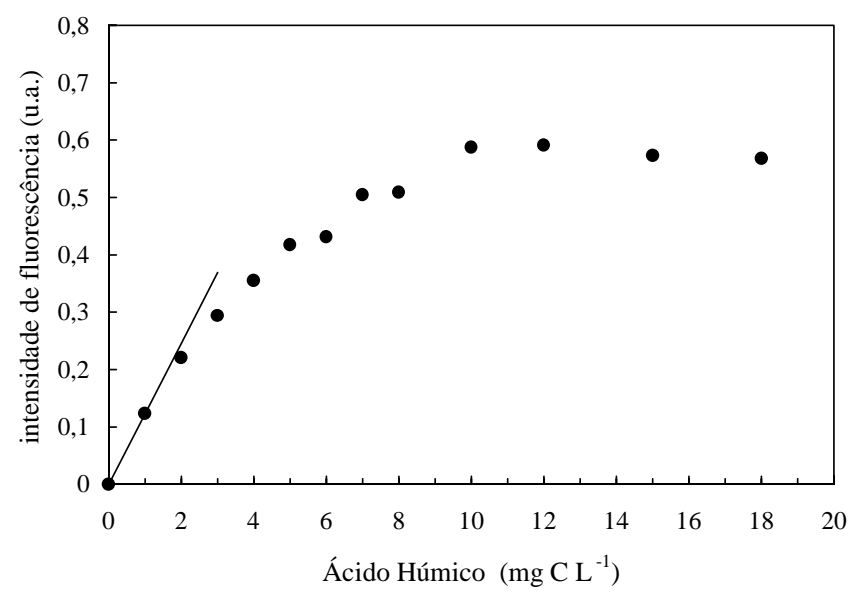

Figura 4. Intensidade de fluorescência de emissão em $441 \mathrm{~nm}$ (unidades arbitrárias) para diversas concentrações de ácido húmico. A reta foi construída através da regressão linear dos dois primeiros pontos.

Como o reator foi construído com o objetivo de destruir a matéria orgânica presente nos mais diversos tipos de amostras naturais, sua eficiência foi também testada em meio salino (Figura 5). Para tal, uma solução de $\mathrm{AH} 8 \mathrm{mg} \mathrm{C} \mathrm{L}^{-1}$ foi preparada num meio contendo $32 \mathrm{~g} \mathrm{NaCl}, 14 \mathrm{~g} \mathrm{MgSO}_{4} .7 \mathrm{H}_{2} \mathrm{O}$ e $0,2 \mathrm{~g} \mathrm{NaHCO}_{3}$ diluídos em $1 \mathrm{~L}$ de água desionizada. Esta solução tem salinidade equivalente a 34,2 (escala de salinidade 
prática $)^{15}$, que é muito comum em ambientes marinhos. A solução salina mostrou uma maior atenuação da fluorescência inicial, provavelmente devido à complexação dos grupos fluoróforos com os metais adicionados ${ }^{10}$. Os complexos formados se mostraram mais resistentes à foto-oxidação, aumentando em 2,5 vezes o tempo de irradiação necessário para atingir uma eficiência de $96 \%$. De modo similar, Jardim e Campos ${ }^{16}$ observaram uma forte inibição do processo oxidativo após promover a complexação da matéria orgânica com cobre em amostras de ambientes salinos e de água doce.

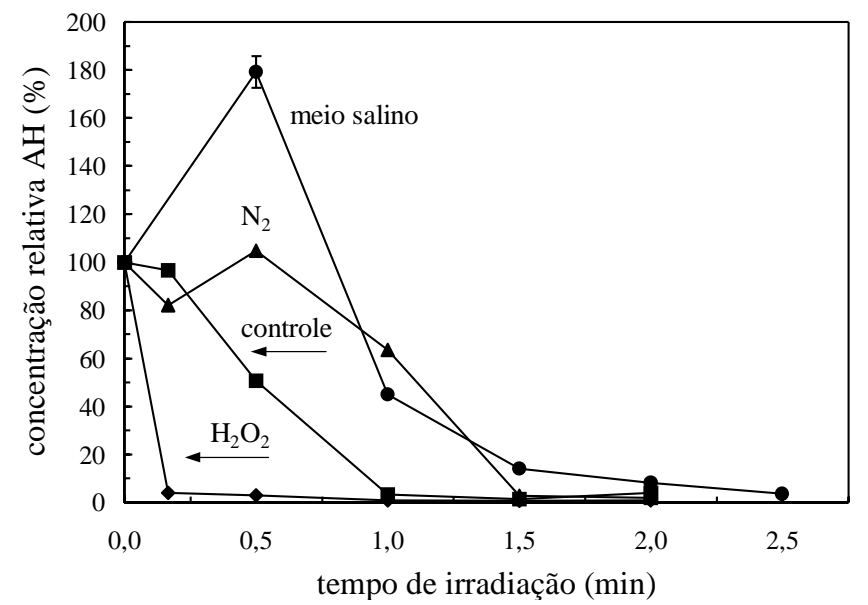

Figura 5. Concentração relativa para soluções de AH $8 \mathrm{mg} C \mathrm{~L}^{-1}$ expressa como porcentagem do sinal inicial de fluorescência de emissão em $441 \mathrm{~nm}$, de acordo com o tempo e irradiação. Uma alíquota foi mantida como controle (ם), e as demais sofreram alterações antes de serem submetidas à irradiação: solução borbulhada durante 10 minutos com $\mathrm{N}_{2}(\boldsymbol{\Delta})$; adição de $\mathrm{H}_{2} \mathrm{O}_{2} 10 \mathrm{mmol} \mathrm{L}^{-1}(\boldsymbol{\nabla})$; solução preparada em meio salino (0). A irradiação da solução em meio salino foi realizada em triplicata, sendo mostrados a média e desvio padrão relativo para cada intervalo de tempo.

O consumo de oxigênio dissolvido nas reações fotoquímicas em águas naturais tem sido apontado como uma importante perda deste gás no ambiente aquático, porém, esta perda é muitas vezes negligenciada nos cálculos de balanço de mas$\mathrm{sa}^{17}$. A importante participação do oxigênio dissolvido na fotólise da matéria orgânica pode ser observada na Figura 5, onde se nota uma drástica queda na taxa de oxidação da solução de $\mathrm{AH}$ previamente borbulhada com $\mathrm{N}_{2}$. De forma análoga, Alberici e Jardim ${ }^{18}$ observaram um aumento de 33 a $62 \%$ na taxa de fotodegradação de uma solução de fenol na presença de $\mathrm{TiO}_{2}$, quando esta era continuamente borbulhada com oxigênio. Alternativamente, a adição de $\mathrm{H}_{2} \mathrm{O}_{2}$ em solução pode funcionar como uma fonte de oxigênio molecular e de radicais hidroxila, que são produzidos a partir da decomposição fotoquímica do $\mathrm{H}_{2} \mathrm{O}_{2}{ }^{19}$. A mineralização da solução de $\mathrm{AH} 8$ $\mathrm{mg} \mathrm{C} \mathrm{L}^{-1}$ foi acelerada em pelo menos 6 vezes após a adição de $\mathrm{H}_{2} \mathrm{O}_{2} 10 \mathrm{mmol} \mathrm{L}^{-1}$ (Figura 5), demonstrando o grande poder oxidante deste composto. Visto que em alguns ambientes naturais pode-se encontrar altas concentrações de matéria orgânica, soluções de ácido húmico contendo $30 \mathrm{mg} \mathrm{C} \mathrm{L}^{-1}$ foram irradiadas na ausência e presença de $\mathrm{H}_{2} \mathrm{O}_{2} 10 \mathrm{mmol} \mathrm{L}^{-1}$. Após
7 horas de irradiação, a solução sem adição de $\mathrm{H}_{2} \mathrm{O}_{2}$ apresentou uma perda de fluorescência de apenas $4 \%$, comparada com $95 \%$ para a solução contendo $\mathrm{H}_{2} \mathrm{O}_{2}$. Como já foi discutido anteriormente, a adição de reagentes às amostras de águas naturais antes da análise de metais traços não é aconselhável devido ao seu alto potencial de contaminação. Porém, esse artifício pode ser de grande valor para ambientes ricos em material húmico, como águas de rios e lagos produtivos, que por sua vez são relativamente ricos em metais pesados. O reator aqui desenvolvido, assim como os princípios de fotoquímica aqui descritos podem ser extrapolados e aplicados para os mais diversos tipos de ambientes naturais ou não.

\section{Aplicação do reator na avaliação da especiação química do cobre em amostras naturais}

A determinação do cobre eletroquimicamente lábil por voltametria de redissolução catódica foi realizada nas amostras apenas filtradas, enquanto que a concentração total do cobre dissolvido foi avaliada após a foto-destruição dos complexos orgânicos presentes em solução. Amostras de águas naturais superficiais de 3 ambientes bastante distintos entre si foram coletadas na região de Florianópolis (Santa Catarina) com o objetivo de avaliar a eficiência do reator aqui construído, na destruição da matéria orgânica natural: 1) Lagoa do Peri, que é um corpo de água doce, 2) Lagoa da Conceição, de água salobra e 3) Praia do Costão do Santinho, com salinidade típica de água do mar (Tabela 1). Apesar de se ter verificado que 2,5 horas de irradiação foram suficientes para destruir mais de $97 \%$ de uma solução de $\mathrm{AH} 8 \mathrm{mg} \mathrm{C} \mathrm{L}^{-1}$ em meio salino (Figura 5), optou-se por irradiar as amostras naturais por 4 horas, prevendo a presença de complexos metálicos e interferentes orgânicos resistentes à fotodegradação. Não houve alteração na concentração de cobre dissolvido total para amostras da Lagoa da Conceição quando irradiadas por 3 ou 4 horas, demonstrando que 3 horas são suficientes para total destruição da matéria orgânica nestas amostras.

Um grande aumento na concentração de cobre dissolvido após a destruição da matéria orgânica foi constatado nas 3 amostras analisadas (Tabela 1). A possibilidade de contaminação das amostras durante o processo de irradiação foi descartada com a realização de brancos antes e depois da irradiação de alíquotas de água Milli-Q. Na Lagoa do Peri, verificou-se que $79 \%$ do cobre dissolvido estava presente na forma de fortes complexos orgânicos (não lábeis), comparado com 59\% na Lagoa da Conceição e $85 \%$ na água do mar. Visto que a fração tóxica do cobre relaciona-se com aquela encontrada na forma lábil (biodisponível), é fundamental avaliar a concentração do metal complexado pela matéria orgânica para se poder estimar a toxicidade do meio. Os resultados de cobre aqui obtidos, além de comprovar a eficiência do reator artesanal na destruição da matéria orgânica natural de diferentes ambientes, demonstra a importância da destruição da matéria orgânica na avaliação da especiação química de metais em ambientes aquáticos.

\section{CONCLUSÕES E CONSIDERAÇÕES FINAIS}

Dada à complexidade de se avaliar a concentração da matéria orgânica presente em amostras naturais, e, visto que grande parte da matéria orgânica natural é formada por substâncias

Tabela 1. Salinidade em escala de salinidade prática, e concentração em nmol L ${ }^{-1}$ de cobre lábil, cobre dissolvido total e cobre complexado com a matéria orgânica para amostras de água de distintos ambientes aquáticos.

\begin{tabular}{lccc}
\hline Local & Salinidade & Cu lábil & Cu dissolvido total \\
\hline Lagoa do Peri & 0,0 & 1,5 & 7,3 \\
Lagoa da Conceição & 16,8 & 2,9 & 7,1 \\
Praia Costão do Santinho & 35,2 & 0,7 & 4,8 \\
4,1 & 4,8 \\
\hline
\end{tabular}


húmicas, este trabalho utilizou soluções de ácido húmico comercial como modelo de composto orgânico de alta massa molecular. Desta forma, a otimização do reator pode ser realizada através de medidas de intensidade de emissão de fluorescência, com detecção de até $0,01 \mathrm{mg} \mathrm{C} \mathrm{L} \mathrm{L}^{-1}$.

As concentrações de carbono orgânico dissolvido em águas marinhas variam dentro de uma faixa relativamente restrita, isto é, de 1 a $4 \mathrm{mg} \mathrm{C} \mathrm{L}^{-1}$, sendo esperadas as maiores concentrações em águas costeiras ${ }^{4}$. Uma solução de $\mathrm{AH} 4 \mathrm{mg} \mathrm{C} \mathrm{L} \mathrm{L}^{-1}$ levou apenas 30 minutos para degradar, porém em meio salino o tempo de irradiação para atingir o mesmo percentual de fotodegradação chegou a ser 2,5 vezes maior. Devido à natureza refratária da matéria orgânica natural, e à possível presença de poluentes orgânicos de origem antrópica, sugere-se o uso de 3 horas de irradiação para assegurar completa destruição da matéria orgânica em águas marinhas costeiras. Outro motivo que demonstra a necessidade de se estender o tempo de irradiação é a presença de distintos mecanismos de fotólise, evidenciados pela grande variação da taxa de destruição das soluções de ácido húmico irradiadas concomitantemente. De acordo com Chester ${ }^{4}$, em rios e lagos produtivos pode-se encontrar concentrações de carbono orgânico dissolvido tão altas quanto $50 \mathrm{mg} \mathrm{C} \mathrm{L}^{-1}$. Para águas com elevadas concentrações de matéria orgânica, a adição de $\mathrm{H}_{2} \mathrm{O}_{2}$ imediatamente antes da irradiação pode ser uma alternativa para acelerar o processo de fotodegradação. Nessas águas também se espera que as concentrações de metais sejam relativamente altas, e portanto, uma possível contaminação pela adição de reagentes pode ser quantificada. A elevação da temperatura também auxilia no processo de oxidação da matéria orgânica, sendo que em $\sim 70{ }^{\circ} \mathrm{C}$ foi possível atingir grande eficiência sem perda de massa. A concentração de cobre após a irradiação das amostras naturais aqui avaliadas foi até 7 vezes maior que nas amostras sem irradiar, demostrando a presença de complexos organo-metálicos não lábeis nos ambientes estudados.

A destruição da matéria orgânica para o estudo da especiação química de metais traços é indispensável quando se utiliza a voltametria de redissolução catódica ou anódica. Comparado com os métodos de digestão úmida, o uso de uma fonte de ultravioleta para oxidação da matéria orgânica minimiza os riscos de contaminação de amostras com baixas concentrações de metais traços. Este estudo demonstra que o reator aqui construído destrói com grande eficiência, tanto a matéria orgânica de amostras naturais, como o ácido húmico comercial, com a vantagem adicional de ser de fácil construção, empregar material de fácil aquisição e ter um baixo custo.

\section{AGRADECIMENTOS}

Os autores são gratos ao CNPq pela concessão de bolsa de Pesquisadora Visitante para a $\operatorname{Dr}^{\mathrm{a}}$ M. Lúcia A. M. Campos, ao aluno de doutorado Marcelo Giovanela pelo apoio durante as análises de fluorescência, e ao graduando Juliano Zanette pela confecção do conversor do ventilador.

\section{REFERÊNCIAS}

1. Achterberg, E. P.; Braungardt, C.; Anal. Chim. Acta 1999, $400,381$.

2. van den Berg, C. M. G. In Chemical Oceanography; Riley, J. P., Ed.; Academic Press; London, 1988, p 198.

3. Vasconcelos, M. T. S. D.; Leal, M. F. C.; Anal. Chim. Acta 1997, 353, 189.

4. Chester, R.; Marine Geochemistry; Unwin Hyman; London, 1990.

5. Frimmel, F. H.; Env. International 1994, 20, 373.

6. Achterberg, E. P.; van den Berg, C. M. G.; Anal. Chim. Acta 1994, 291, 213.

7. Sugimura, Y.; Suzuki, Y.; Mar. Chem. 1988, 24, 105.

8. Nogueira, R. F. P.; Guimarães, J. R.; Water Res. 2000, 34,895 .

9. Jardim, W. F.; Pasquini C.; Guimarães, J. R.; Faria L. C.; Wat. Res. 1990, 24, 351.

10 de Souza Sierra, M. M.; Giovanela, M.; Donard, O. F. X.; Belin, C.; Quim. Nova 1996, 10, 294.

11. Campos, M. L. A. M.; van den Berg, C. M. G.; Anal. Chim. Acta 1994, 284, 481.

12. Yokoi, K.; Tomisaki, T.; Koide, T.; van den Berg, C. M. G.; Fresenius J. Anal. Chem. 1995, 352, 547.

13. Maritn-Goldberg, M.; Schuman, M. S.; Chem. Speciation Bio. 1989, 1, 19.

14. de Souza Sierra, M. M.; Donard, O. F. X.; Lamotte, M.; Mar. Chem. 1997, 58, 51.

15. Grasshoff, K.; Methods of Seawater Analysis; Verlagchemie; New York, 1976.

16. Jardim, W. F.; Campos, M. L. A. M.; Sci. Total Environ. 1988, 75, 243.

17. Laane, R. W. P. M.; Gieskes, W. W. C.; Kraay, G. W.; Eversdijk, A.; Netherlands J. Sea Res. 1985, 19, 125

18. Alberici, R. M.; Jardim, W. F.; Wat. Res., 1994, $28,1845$.

19. Turchi, C. S.; Ollis, D. F.; J. Catal. 1990, 122, 178. 